\title{
FAKTA SEJARAH DALAM CERPEN INDAHNYA PERSATUAN KARYA ODHY'S
}

\section{HISTORICAL FACTS IN INDAHNYA PERSATUAN SHORT STORY BY ODHY'S}

\author{
Khairul Fuad \\ Balai Bahasa Kalimantan Barat \\ khairulfuad297@gmail.com
}

\begin{abstract}
ABSTRAK
Penelitian ini bertujuan mengetahui fakta-fakta sejarah di balik cerpen Indahnya Persatuan karya Odhy's. Sebagai karya sastra tidak terbebas dari ruang dan waktu maka konteks-konteks pasti melingkupinya. Konteks sejarah merupakan permasalahan yang terdapat di dalam cerpen tersebut pascapembacaan awal. Mengetahui sekaligus menjawab konteks sejarah digunakan metode kualitatif dengan teori kontekstual dan sosio-historis untuk mengungkapkan fakta-fakta sejarah yang dimunculkan. Kemudian, hasil penelitian didapatkan fakta sejarah terkait dengan peristiwa kerusuhan horisontal antara Dayak dan Madura. Selain itu, fakta-fakta lain juga didapatkan sebagai runtutan fakta sejarah kerusuhan tersebut. Hasil penelitian ini diperoleh simpulan bahwa cerpen Indahnya Persatuan memuat unsur fakta-fakta sejarah yang terjadi di Kalimantan Barat. Melalui hasil ini dapat disebutkan bahwa proses karya sastra terkait erat dengan kontekstualitas, baik berhubungan dengan waktu maupun tempat.
\end{abstract}

Kata Kunci: Dayak, Madura, fakta sejarah, dan cerpen.

ABSTRACT
This research aims to know the historical facts behind the Odhy's's sort story Indahnya Persatuan. As the work of literature relates certainly to the space and time so those contexts will surround it certainly. Historical context denotes the problem which fills in that short story through reading first. Knowing included answering the historical context is used method of qualitative with theory of contextuality and socio-history for revealing the historical facts were appeared. Then, the result of research was found the historical fact related with the horizontal conflict between Dayaknese and Madurese. The other hand, the other historical facts were found as chronological history of that horizontal conflict. The conclusion of result of research was the short story Indahnya Persatuan containing the elements of historical facts were happened in West Borneo. Through those result can be mentioned that the process of literature work related deeply to contextuality, either the space or the time.

Keywords: Dayak, Madurese, historical fact, and short story.

\section{PENDAHULUAN}

Beberapa karya sastra mendasarkan penceritaan dan ungkapannya dengan fakta sejarah, misalnya, Novel Kapal Terbang Sembilan karya M. Yanis, sastrawan Kalimantan Barat, didasarkan oleh fakta sejarah, yaitu pendudukan 
Jepang di Kalimantan Barat. (Fuad dkk, 2008: 547). Dalam konteks nasional, karya-karya Pramudya Ananta Toer, Umar Khayam, dan Y.B. Mangunwijaya juga mendasarkan pada fakta sejarah.

Fakta sejarah sendiri merupakan peristiwa yang sungguh terjadi dan menjadi bagian tidak terpisahkan dari perjalanan sebuah komunitas masyarakat, bangsa, dan negara. Sementara itu, peristiwa yang dialami oleh seseorang hanya melibatkan individu saja sulit dikategorikan sebagai sejarah, terkecuali melibatkan sebuah komunitas secara luas. Fakta sejarah bisa dikatakan sebagai peristiwa nyata melibatkan unsur masyarakat secara luas dan berdampak sangat berarti.

Secara instrinsik karya sastra, unsur-unsur yang dibangun tidak keseluruhan bersifat fiksi, artinya, sebagian memiliki relevansi historis, yang dengan sendirinya dapat disejajarkan dan memiliki ekuivalensi dengan fakta-fakta sejarah umum, terutama sejarah sosial (Ratna, 2013: 240). Fakta sejarah dengan keterlibatan masyarakat secara luas menjadi unsur terpenting sebuah karya sastra, tidak fakta sejarah dengan dampak kecil di masyarakat.

Ditambah, struktur fiksional karya sastra mendapatkan maknanya yang sesungguhnya semata-mata melalui relevansinya dengan struktur sosiohistoris yang melatarbelakanginya (Ratna, 2013: 243). Peristiwa sosiohistoris sebagai fakta sejarah pada sebuah komunitas masyarakat sering menjadi latar-belakang yang dihadirkan sastrawan dalam karyanya. Kehadiran fakta sejarah tersebut tentu tidak sepenuhnya fakta karena kebutuhan karya fiksional itu sendiri.

Kalimantan Barat sebagai sebuah wilayah tidak terlepas dengan gambaran itu sesuai posisi dan kondisi, baik khas maupun sama dengan wilayah lain yang melekat. Oleh karena itu, dengan komunitas heterogen jadi sebab grafik sosialbudaya cenderung berfluktuasi di wilayah Kalimantan Barat. Galib diketahui bahwa Kalimantan Barat didiami oleh masyarakat dengan latar etnis yang beragam.

Dengan demikian, Kalimantan Barat memang rawan konflik kepentingan berdasar pada ragam etnis yang tentunya memiliki ragam kepentingan yang berbeda juga. Menurut Arkanudin, di samping orang Dayak terdapat orang Melayu, Banjar, Bugis, Jawa, Sunda, Madura, Arab, dan Cina yang mendiami Kalimantan Barat (Arkanudin, 2006: 185, http://ejournal.unisba.ac.id). Ragam etnis berpotensi memantik konflik pada akar rumput karena berdasar pada sosialbudaya yang berbeda.

Dalam catatan sejarah pernah terjadi konflik berdasar pada perbedaan etnis di Kalimantan Barat. Dalam catatan Syarif Ibrahim Al-Qadri sosiolog Universitas Tanjungpura, drama kerusuhan massal yang terjadi di penghujung 1996 itu sesungguhnya merupakan hasil tumpukan dari berbagai persoalan yang telah terakumulasi (Liputan Adil, 2011: 2). Dalam hal ini terbukti bahwa konflik massal antaretnis pernah pecah di Kalimantan Barat.

Pada gilirannya, aspek sosial-budaya dengan wujud peristiwa konflik antaretnis sebagai fakta sejarah dijadikan latar dalam sebuah karya sastra. Ada banyak karya sastra yang mendasarkan penceritaan dan ungkapannya dengan fakta sejarah. Misalnya, Novel Kapal Terbang Sembilan karya M. Yanis, sastrawan Kalimantan Barat, didasarkan oleh fakta sejarah, yaitu pendudukan Jepang di Kalimantan Barat. (Fuad dkk, 2008: 547). 
Termasuk juga, Odhy's dalam jajaran sastrawan Kalimantan Barat pernah membangun karya sastra berdasarkan dengan fakta sejarah. Indahnya Persatuan judul cerpennya terindikasi kuat dilatari oleh fakta sejarah, yaitu peristiwa konflik antarertnis yang pernah terjadi di Kalimantan Barat. Realitas sosial dalam bingkai sejarah menjadi fakta menarik bagi Odhy's untuk dieksplorasi membangun karya sastra.

Karya sastra merupakan tiruan dunia (mimetis) dan dapat dipastikan mengambil fenomena di lingkungan sekitarnya atau lingkungan terdekatnya sebagai sumber pengembangan cerita. Sastra merupakan tiruan atau pemaduan antara kenyataan dengan imajinasi pengarang atau hasil imajinasi pengarang yang bertolak dari suatu kenyataan (Semi, 2013: 42). Pengarang nyatanya tidak lepas dari kenyataannya.

Fenomena alam, dengan lingkungan dan masyarakatnya, tidak bisa lepas dari sebuah karya sastra. Kemunculan ekokritik tidak lepas dari fenomena lingkungan dan kritik-sosial tidak terlepas dari dinamika masyarkat yang terus berubah. Keduanya merupakan kaca-mata untuk melihat karya sastra yang berbasis pada kenyataan lingkungan dan masyarakat. Kenyataan bagian terpenting yang menghidupkan karya sastra.

Fakta sejarah bagian dari fenomena dinamika masyarakat tidak lepas juga partisipasinya dalam membangun unsur kesastraan. Fakta sejarah ini yang kemudian untuk diungkapkan di balik Indahnya Persatuan, cerpen karya Odhy's. Fakta-fakta sejarah apa yang terkandung di balik cerpen tersebut, terkait dengan perjalanan sejarah di Kalimantan Barat. Selain itu, upaya memperkukuh keseriusan Odhy's dalam membangun sebuah karya sastra.

Terkait dengan penelitian sebelumnya adalah memperkaya apresiasi karya sastra yang telah ditorehkan oleh Odhy's. Religiusitas merupakan pendekatan yang pernah dilakukan untuk menganalisis karyanya sebagai langkah apresiasi, termasuk juga sosiologis sebagai pendekatan yang pernah dilakukan. Di sisi lain, apresiasi ini juga memperkaya sekaligus memperkukuh khazanah kesastraan kalimantan Barat.

Dengan demikian, perlu rumusan masalah sebagai pengayaan apresiasi karya sastra Odhy's. Pengungkapan fakta sejarah merupakan rumusan masalah penelitian ini, yang diperoleh melalui cerpen Indahnya Persatuan. Rumusan masalahnya dengan pertanyaan, bagaimana Odhy's mengungkapkan fakta-fakta sejarah di dalam cerpen tersebut. Fakta-fakta tersebut kemudian dijelaskan di dalam pembahasan dan dijawab di simpulan.

Pendekatan historis merupakan langkah penting untuk mengembangkan operasional rumusan masalah tersebut. Terkait pendekatan historis memang telah lama digunakan dan justru telah lama juga memiliki sejarahnya. Pada abad ke-17 John Dryden (1631-1700) yang mengatakan pentingnya pendekatan historis dan dipandang sebagai Bapak Kritik Sastra Inggris oleh kritikus sesudahnya (Mahayana, 2005: 365).

Dalam esainya yang terkenal An Essay of Dramatis Poetry (Esai tentang Puisi Dramatik, 1668), Dryden mengatakan, "Keunggulan suatu zaman seyogianya ditinjau dari sudut sejarah, sebab setiap zaman hakikatnya adalah juru bicara bagi zamannya (Mahayana, 2005: 365). Dari esai yang ditulis oleh Dryden 
Tuah Talino

Tahun XIII Volume 13 Nomor 1 Edisi 5 Juli 2019

ISSN 0216-079X

Balai Bahasa Kalimantan Barat

diturunkan konsep-konsep terkait pendekatan historis sehingga memunculkan konsep pandangan historisisme baru (new historicism).

\section{METODE}

Metode yang digunakan adalah metode kualitatif dengan menggambar atau mendeskripsikan data berupa naskah tulisan. Dipilih metode ini dengan pertimbangan bahwa data yang dianalisis berupa tulisan, tidak berupa angka. Teori yang digunakan adalah sastra kontekstual yang dikembangkan oleh Ariel Heryanto sebagai pemahaman atas kesusasteraan dalam kaitannya dengan konteks sosio-historis.

Sastra kontekstual adalah sastra yang sesuai dengan konteks sosio-historis masyarakat di sekeliling tempat terciptanya karya tersebut (Heryanto, 1985: 43 di dalam Santoso dan Djamaris, 2014: 180). Berbasis pada teori sastra kontekstual maka Indahnya Persatuan muncul terdapat kesesuaian dengan sosio-historis masyarakat Kalimantan Barat, terutama masyarakat Dayak dan Madura. Peristiwa yang pernah menimpa kedua masyarakat ini merupakan kontekstualisasinya.

Metode dan teori tersebut digunakan untuk memperoleh fakta sejarah yang terdapat di dalam cerpen Indahnya Persatuan. Fakta sejarah terkait peristiwa yang menimpa kedua masyarakat tersebut beserta dengan keterkaitannya. Fakta sejarah memberikan informasi tentang suatu peristiwa yang terjadi di masa lampau. Fakta berasal dari bahasa Latin, factus dan facerel, yang artinya selesai atau mengerjakan. Fakta sejarah adalah fakta-fakta yang berhubungan langsung dengan peristiwa sejarah yang kita teliti (Madjid dan Wahyudhi, 2014: 36).

Menurut Mahayana (2005: 361), karya sastra dan sejarah, keduanya bersumber dari peristiwa atau pengalaman masa lalu yang sudah terjadi maka karya sastra dan sejarah menempatkan dirinya sebagai karya yang merekam peristiwa. Oleh karena itu, fakta sejarah menjadi titik-temu untuk mempertemukan cerpen Odhy's tersebut dan peristiwa sejarah yang pernah di Kalimantan Barat.

\section{PEMBAHASAN}

Odhy's mengungkapkan beberapa fakta sejarah di dalam cerpen Indahnya Persatuan, sekaligus fakta sejarah tersebut dijadikan inspirasi terlahirnya cerpen tersebut. Fakta sejarah sebagai peristiwa yang memilukan dan mengoyak-oyak rasa kemanusiaan, terlepas dari penafsiran peristiwa tersebut yang tentunya beragam. Tampaknya dalam hal ini, Odhy's berkeinginan meneroka dari sisi kemanusiaan saja meski termasuk bagian dari penafsiran.

Tentunya, sebagai sebuah karya sastra, cerpen tersebut terdapat dua sisi yang muncul, selain fakta sejarah, yaitu imajinasi yang tidak dapat dinafikan. Bukan sebagai karya sejarah murni maka terdapat sisi lain untuk mengembangkan fakta sejarah sebagai faktor pemicu cerpen tersebut. Fakta sejarah dan imajinasi membangun cerpen tersebut menjadi utuh. Imajinasi sendiri merupakan daya pikir untuk membayangkan kejadian berdasarkan kenyataan atau pengalaman seseorang (Amalia dkk, KBBI Edisi V 2017: 630).

Dalam Indahnya Persatuan dibangun imajinasi seputar hubungan asmara antara dua insan berbeda jenis dan etnis. Salewan seorang pemuda Madura, 
sedangkan Sonik seorang gadis Dayak, yang menjalin asmara sejak di bangku SMA sampai berlanjut ke Perguruan Tinggi. Salewan menaruh suka kepada Sonik saat berkunjung ke daerah komunitas masyarakat Dayak, diajak oleh kepala adat ke Pancak, tempat pemujaan, dan ungkapkan kesukaan kepada Sonik.

"Dan di atas sana kita boleh mengucapkan niat kita kepada Jubata, niscaya beliau akan mengabulkan niat itu. Yuk kita ke sana." Dimulai langkah kepala adat, maka mereka pun menaiki tangga bangunan Pancak yang tinggi.

Saat boleh membisikkan niat, diam-diam Salewan berbisik: "Kalau Tuhan berkenan aku ingin berjodoh dengan gadis sepolos Sonik" Dia heran, kenapa hal itu yang dia bisikkan (Odhy's, (tanpa tahun): 5).

Akan tetapi, perjalanan asmara mereka berdua sempat terusik oleh peristiwa kerusuhan horizontal yang melibatkan kedua etnis Sonik dan Salewan, Dayak dan Madura. Untungnya, peristiwa tersebut tidak berdampak berarti (signifikan) hubungan mereka berdua, justru menyayangkan kejadian itu harus terjadi. Peristiwa kerusuhan tersebut ternyata bagian dari fakta sejarah, bukan bagian dari imajinasi yang dibangun oleh Odhy's di cerpen tersebut.

\section{PERISTIWA KERUSUHAN DAYAK-MADURA}

Sebagai bagian dari bangunan Indahnya Persatuan diungkapkan secara eksplisit oleh Odhy's peristiwa tersebut. Peristiwa tersebut sebenarnya deretan kerusuhan horizontal yang pernah terjadi di Kalimantan Barat. Risiko paling terburuk memang harus ditanggung oleh wilayah yang dihuni oleh multietnis dengan kesulitan membangun kepentingan bersama. Peristiwa tersebut yang diungkapkan secara eksplisit sebagai berikut.

Sebagai 'orang kota' yang berpendidikan mereka tak membenarkan adanya permusuhan di antara dua suku yang terjadi di awal tahun 1976. Bukan saja lantaran permusuhan semacam itu tidak sesuai dengan sila di dalam Pancasila, namun lebih dari itu. Keadaan mereka jadi tersudut. Bukankah Sonik itu gadis Dayak; dan Salewan pemuda Madura; sedang di kampung-kampung sana berlangsung 'peperangan' di antara kedua suku tersebut? (Odhy's, (tanpa tahun): 4).

Sebelum peristiwa memilukan 1976 yang disebutkan oleh Odhy's, peristiwa yang sama pernah terjadi diawali pada 1950 yang menyebabkan perkelahian massal dengan korban dalam jumlah besar. Tak diketahui persis penyebabnya. Peristiwa itu berlanjut pada 1967 antara Dayak dan Tionghoa, meletus kembali Dayak dan Madura pada 1968 (Liputan 6, 2001: https://www.liputan6.com).

Kemudian, peristiwa sama kembali meletus pada 1976 sebagaimana yang disebutkan oleh Odhy's di Indahnya Persatuan. Peristiwa tersebut merupakan fakta sejarah pilu yang pernah melanda Kalimantan Barat. Sebagai fakta sejarah tentunya akan menimbulkan berbagai tafsir atas akar permasalahan yang memicunya. Namun demikian, terkait penelitian ini adalah ansich fakta sejarah yang melatari kemunculan cerpen ini.

Tentunya, sebagai fakta sejarah diungkapkan peristiwa 1976 tanpa adanya upaya tafsir mendalam. Peristiwa 1976 dipantik oleh pembunuhan atas nama Cangkeh yang dilakukan oleh beberapa orang Madura. Orang-orang Madura marah atas tindakan menghardik Cangkeh kepada seorang Madura yang menyabit 
rumput di rumahnya. Peristiwa tersebut terjadi di Sungai Pinyuh (Liputan 6, 2001: https://www.liputan6.com). Sungai Pinyuh sekarang merupakan kecamatan di Kabupaten Mempawah, dulunya bernama Kabupaten Pontianak.

Tabel catatan Tanasaldy disebutkan bahwa peristiwa konflik Dayak-Madura 1976 merupakan rangkaian dari rangkaian-rangkaian peristiwa yang sama di Kalimantan Barat. Disebutkan bahwa konflik 1976 terjadi di Sungai Pinyuh yang saat itu nomenklatur wilayahnya Pontianak belum Kabupaten Mempawah. Sama halnya, pemicu konflik disebabkan oleh pembunuhan orang Dayak oleh orang Madura yang mengambil rumput di tanah orang Dayak tersebut (Tanasaldy, 2012: 217).

Pemaparan tabel di bawah memperkuat bahwa Odhy's dalam Indahnya Persatuan mendasarkan pada fakta sejarah sebagai kontekstualisasi sastra, terutama sekali peristiwa 1976. Dari peritiwa tersebut terungkap peristiwaperistiwa lain yang mengoyak rasa kemanusian, namun yang perlu sebagai catatan agar peristiwa sama tidak terulang lagi demi indahnya persatuan.

\begin{tabular}{|l|l|l|}
\hline Tahun & Lokasi & Pemicu \\
\hline 1950 & $\begin{array}{l}\text { Samalantan } \\
\text { (Bengkayang) }\end{array}$ & $\begin{array}{l}\text { Perkelahian antara orang Dayak dan Orang } \\
\text { Madura }\end{array}$ \\
\hline 1952 & Lokasi tidak diketahui & $\begin{array}{l}\text { Pencurian bubu orang Dayak oleh orang } \\
\text { Madura }\end{array}$ \\
\hline 1967 & $\begin{array}{l}\text { Toho (Pontianak kini } \\
\text { Mempawah) }\end{array}$ & $\begin{array}{l}\text { Pembunuhan sepasang orang tua Dayak di } \\
\text { sebuah wilayah di Toho }\end{array}$ \\
\hline $\begin{array}{l}\text { Ajungan (dulu } \\
\text { Pontianak kini }\end{array}$ & $\begin{array}{l}\text { Pembunuhan orang Dayak di sebuah wilayah } \\
\text { di Sungai Pinyuh. Dayak menolak proses } \\
\text { permohonan kepemilikan orang Madura atas } \\
\text { tanah }\end{array}$ \\
\hline 1976 & $\begin{array}{l}\text { Sungai Pinyuh (dulu } \\
\text { Pontianak kini } \\
\text { Mempawah) }\end{array}$ & $\begin{array}{l}\text { Pembunuhan orang Dayak oleh orang Madura } \\
\text { yang mengambil rumput di pekarangannya }\end{array}$ \\
\hline 1979 & $\begin{array}{l}\text { Singkawang } \\
\text { Samalantan (dulu } \\
\text { Bengkayang) }\end{array}$ & $\begin{array}{l}\text { Pembunuhan polisi Dayak oleh orang Madura. } \\
\text { Orang Dayak itu memperingatkan saudara } \\
\text { perempuannya untuk tidak pergi keluar malam } \\
\text { bersama orang Madura }\end{array}$ \\
\hline 1982 & $\begin{array}{l}\text { Pembunuhan orang Dayak oleh orang Madura. } \\
\text { Orang Dayak itu memohon orang Madura } \\
\text { untuk hati-hati saat merumput untuk tidak } \\
\text { Bengerusak tanaman padi }\end{array}$ \\
\hline Raya)
\end{tabular}




\begin{tabular}{|c|c|c|}
\hline 1992 & $\begin{array}{l}\text { Pakucing (Samalantan } \\
\text { Bengkayang) }\end{array}$ & $\begin{array}{l}\text { Pemerkosaan perempuan Dayak oleh orang } \\
\text { Madura }\end{array}$ \\
\hline 1993 & Kota Pontianak & $\begin{array}{l}\text { Perkelahian antara pemuda Dayak dan pemuda } \\
\text { Madura }\end{array}$ \\
\hline 1994 & $\begin{array}{l}\text { Tumbang Titi } \\
\text { (ketapang) }\end{array}$ & $\begin{array}{l}\text { Penusukan orang Dayak oleh pekerja } \\
\text { konstruksi jalan yang beretnis Madura }\end{array}$ \\
\hline 1996 & $\begin{array}{l}\text { Dimulai dari Sanggau } \\
\text { Ledo (Bengkayang) } \\
\text { tersebar di wilayah lain }\end{array}$ & $\begin{array}{l}\text { Perkelahian pemuda Dayak dan pemuda } \\
\text { Madura }\end{array}$ \\
\hline 1997 & $\begin{array}{l}\text { Dimulai dari Kota } \\
\text { Pontianak tersebar di } \\
\text { wilayah lain }\end{array}$ & $\begin{array}{l}\text { Seorang pemuda Madura menyerang kompleks } \\
\text { Pancur Kasih }\end{array}$ \\
\hline 1999 & $\begin{array}{l}\text { Dimulai dari Jawai } \\
\text { (Sambas) tersebar di } \\
\text { wilayah lain }\end{array}$ & Konflik antara Melayu/Dayak dan Madura \\
\hline
\end{tabular}

Dalam konteks global dipahami bahwa peristiwa kerusuhan horizontal tidak dibenarkan dari sisi kemanusiaan, hanya akan meninggalkan kebencian yang tak berkesudahan untuk generasi mendatang. Dari konteks keindonesiaan tentunya tidak sesuai dengan prinsip kenegaraan yang tertuang di dalam sila-sila dari Pancasila. Dari konteks cerita dikhawatirkan akan mengganggu hubungan Sonik dan Salewan yang berasal dari dua etnis yang bertikai.

Dalam Indahnya Persatuan diceritakan bahwa kedua insan berbeda jenis dan etnis itu tetap menjalin hubungan asmaranya, tidak terpengaruh oleh peristiwa kerusuhan tersebut. Bahkan, keduanya saling menghormati atas dasar perbedaan yang melekat pada dirinya masing-masing. Melalui cerpen tersebut dapat dipahami bahwa Odhy's tidak mengeneralisasi peristiwa tersebut pada setiap orang yang kebetulan berbeda etnis, kutipan jalinan asmara sebagai berikut.

Nyatanya memang demikian. Sejak di kelas tiga - dan mereka kebetulan sekelas - Salewan dan Sonik menjalin tali percintaan. Entah dikarenakan niat yang dibisikkan pemuda itu di atas Pancak dikabulkan Jubata atau karena perjuangan Salewan yang gigih buat mendapatkan Sonik yang terwujud. Entahlah. Sebab tokh Salewan tak lagi mengungkit-ungkit soal itu. Pokoknya, kemudian semua orang di SMA mereka tahu bahwa Sonik yang gadis Dayak pacarnya Salewan seorang pemuda Madura. Titik.

Dan percintaan di SMA itu setahun kemudian mereka bawa ke kampus. Semakin mapan. (Odhy's, (tanpa tahun): 6).

\section{AKCAYA: MEDIA MASSA LOKAL KALIMANTAN BARAT}

Odhy's mengungkapkan peran media massa ikut berupaya meredam kerusuhan tersebut agar tidak meluas melalui pemberitaan. Pengungkapan ini tidak terlepas pengaruh dari dirinya sendiri yang pernah tergabung sebagai punggawa sebuah media massa lokal dan majalah Jakarta. Odhy's pernah menjadi koresponden dan bekerja sebagai jurnalis di majalah Jakarta dan koran Pontianak (Odhy's. 2006: 174).

Akcaya merupakan media masa lokal yang diungkapkan perannya oleh Odhy's terkait terjadinya kerusuhan tersebut. Saat pecahnya kerusuhan tersebut 
digambarkan bahwa Akcaya menurunkan beritanya terkait kerusuhan tersebut pada cerpen Indahnya Persatuan. Karena memiliki tanggung-jawab sosial, Akcaya dikemukakan dalam memberikan asupan informasi kepada masyarakat pembacanya.

Salewan, saat itu, untuk beberapa jenak, tercenung. Di tangannya terkulai selembar AKCAYA, koran daerah yang membicarakan masalah pertikaian yang berlangsung di kampung-kampung. Permusuhan di antara dua suku Madura dan Dayak semakin panas. Di mana-mana terjadi pembunuhan. Keji dan mengerikan. Teguran dari pejabat setempat tak sedikit pun mereka gubris. Agaknya kedua suku tersebut sudah kerasukan setan pembunuhan (Odhy's: (tanpa tahun): 4).

Akcaya merupakan cikal-bakal Koran Pontianak Post yang kini menjadi barometer jurnalisme media massa di Kalimantan Barat. Menurut Tabrani Hadi, pendiri Akcaya, saat membangun Akcaya pada 1973 silam, tantangannya adalah bagaimana membuat media-cetak yang berisi informasi berkualitas dan dengan tampilan yang cantik (Pontianak Post, "Merawat Kenangan 46 Tahun Pontianak Post”. Sabtu 2 Februari 2019: hlm 1). Rentang lama Akcaya memiliki peran menyertai perkembangan masyarakat Kalimantan Barat.

Menurut Faruk (2018: 192), karya sastra bukan sebagai sebuah teks kebahasaan yang tertutup sebagaimana digambarkan oleh Rene Wellek dan Austin Warren, melainkan sebagai teks yang terbuka yang tidak dapat dilepaskan konteksnya. Bahkan, penggambaran koran Akcaya tidak semata teks yang dihadirkan oleh Odhy's, tetapi konteks sejarah yang menjadi bagian kemasyarakatan Kalimantan Barat.

Oleh karena itu, koran Akcaya merupakan entitas fakta sejarah secara kontekstual sebagai unsur yang memperkuat bangunan imajinasi Indahnya Persatuan secara tekstual. Kisah asmara Sonik dan Salewan sebagai bangunan imajinasi dibungkus oleh fakta sejarah keberadaan koran Akcaya yang mewartakan peristiwa konflik Dayak-Madura di beberapa kampung di Kalimantan Barat. Penggambaran media-massa memang galib memublikasikan berita.

Dalam kronologis waktu terdapat sinkronitas antara keberadaan koran Akcaya dan peristiwa kerusuhan Dayak-Madura. Keberadaan koran Akcaya diketahui pada 1973, sedangkan peristiwa tersebut meletus pada 1976. Dengan demikian, koran Akcaya mewartakan peristiwa tersebut sebagai koran lokal yang menaruh perhatian lebih terhadap berita-berita lokal yang harus diketahui oleh masyarakat lokal Kalimantan Barat.

\section{ANTON SOEDJARWO}

Selanjutnya, Odhy's mengungkapkan fakta sejarah lain di dalam Indahnya Persatuan, yaitu peran yang dilakoni oleh Anton Soedjarwo. Sebagai fakta sejarah tentu bukan bagian dari karya imajinatif, melainkan faktor pendukung memperkuat cerita imajinatif tersebut. Fakta sejarah sudah pasti tidak dalam deretan peristiwa fiktif, tetapi dapat menjadi pemantik (trigger) menghidupkan seolah nyata karya fiksi.

Anton Soedjarwo (1930-1988) merupakan perwira polisi dalam jajaran Kepolisian Republik Indonesia (Polri) dan pernah menjabat di jajaran tertinggi 
Polri sebagai Kepala Kepolisian Negara Republik Indonesia (Kapolri) dalam masa jabatan 1982 s.d. 1986. Terkait Kalimantan Barat, Anton Soedjarwo pernah menjabat Komandan Komando Daerah Kepolisian (Kodak) Kalimantan Barat pada 1974, kemudian 1978 pindah komandan Kodak Sumatera Utara.

Hari masih pagi. Mentari belum lagi menyebarkan butir-butir panasnya. Sebuah derum motor terdengar memasuki halaman rumah kontrakan Sonik yang mungil namun resik.

Salewan yang turun dari motor nampak tergesa-gesa melangkah ke arah pintu. Di tangannya ada selembar koran.

"Soniiiiik!" teriaknya dlam desah suara tak sabar.

Ada suara langkah yang tergopoh-gopoh. Sonik muncul dengan beberapa cucian basah di tangannya.

"Ada apa, Wan? Aku lagi mendedai pakaian yang kemarin sore direndam."

"Tunda dulu semua aktivitasmu," perintah Salewan yakin. "Baca ini." Dia menyodorkan lembar AKCAYA yang dibawanya dari rumah.

"Baca yang mana?" Sonik masih belum mengerti.

"Halaman pertama. Kanan atas. nah, di kolom 3 dan seterusnya itu."

Mata Sonik serta-merta terbelalak. Pada lembar koran itu terbaca sebuah judul yang besar: "Letkol Sudjarwo Akhirnya Berhasil Membawa Misi Perdamaiannya." Lalu di bawahnya ada sub-judul: "Dayak dan Madura Bersatu Kembali." (Odhy's, (tanpa tahun): 6)

Kutipan di atas merupakan cuplikan tentang Anton Soedjarwo terkait kiprahnya meredam konflik Dayak-Madura agar tidak meluas dan berhasil membawa misi perdamaian di antara kedua ertnis tersebut. Korelasi kiprahnya tampak jelas pada masa terjadinya konflik tersebut dengan masa jabatan yang diembannya menjadi orang nomor satu waktu itu di lingkungan kepolisian Kalimantan Barat. Konflik terjadi pada 1976 dan masa jabatannya 1974 s.d. 1978.

Tidak lama di Korps Brimob sebagai komandan pada 6 Juni 1974, Kolonel polisi Anton Soedjarwo pada tahun 1975 dipromosikan menjadi Kepala Daerah Kepolisian XI/Kalimantan Barat. Dengan pangkat Brigadir Jendral Polisi Anton Soedjarwo menjabat sebagai kapolda Kalimantan Barat (Panitia Penulisan Ensiklopedi Kapolri, 2007: 51). Hanya saja sebagai karya imajinatif bukan karya sejarah, Odhy's menyebut sosok Anton Soedjarwo dengan pangkat yang tidak sebenarnya.

Dengan demikian, Odhy's memang memunculkan fakta sejarah dalam Indahnya Persatuan. Sosok Anton Soedjarwo merupakan konteks sejarah, termasuk peristiwa konflik Dayak-Madura dan koran Akcaya, yang mengiri konsep imajinatif kisah asmara antara Sonik dan Salewan. Meskipun cerita rekaan (cerkan) terkonsep dalam cerpen, Odhy's menghadirkan cerita nyata (fakta sejarah). Basis cerita rekaan (imajinatif) dapat disisipkan peristiwa riil (sejarah).

Terdapat korelasi antara cerkan dan fakta sejarah, yaitu pernyataan "Letkol Sudjarwo Akhirnya Berhasil Membawa Misi Perdamaiannya." sebagai judul besar di koran Akcaya. Anton Soedjarwo senantiasa bekerja sama dengan pangdam, gubernur, kepala kejaksaan tinggi, dan berkenalan akrab dengan para pemangku adat, dan ketua etnis lainnya (Panitia Penulisan Ensiklopedi Kapolri, 2007: 52). Tidak mengherankan jika nama Anton Soedjarwo sekarang diabadikan sebagai nama rumah sakit milik institusi kepolisian di Kalimantan Barat. 
Fakta sejarah tersebut menjadi indikasi kuat apresiasi dari kalangan tertentu yang menyebutkan bahwa Odhy's telah bermetamorfosis dari sastra pop ke sastra serius. Indahnya Persatuan meretaskan Odhy's ke dalam metamorfosis dari sastra pop ke sastra serius seperti yang pernah Korrie Layun Rampan lontarkan (Fuad, 2016: 89-90). Kategori sastra serius terdapat pada fakta sejarah di dalam Indahnya Persatuan.

Di sisi lain, fakta sejarah tersebut merupakan latar sejarah dari Indahnya Persatuan, yang bersifat nonimajinatif dan menjadi bagian dari kontekstualisasinya. Kontekstualisasi menurut Zaidan yang disepadankan dengan konstruktivisme sebagai teori yang beranggapan bahwa setiap karya sastra terkondisikan oleh latar sejarahnya (Santoso dan Djamaris, 2014: 181). Oleh karena itu, kondisi sejarah mempengaruhi kemunculan Indahnya Persatuan sebagai fakta sejarah kemudian.

\section{SOSIAL-BUDAYA BERBEDA DAYAK-MADURA}

Peristiwa kerusuhan Dayak-Madura merupakan fakta sejarah primer, sedangkan Akcaya dan Anton Soedjarwo merupakan fakta sejarah sekunder. Peristiwa kerusuhan tersebut menjadi latar sejarah utama cerpen Indahnya Persatuan. Odhy's sebagai sastrawan Kalimantan Barat mengeksplorasi dengan seksama kondisi yang terjadi di sekitar lingkungannya. Peristiwa sejarah tersebut menyita perhatiannya dalam membangun Indahnya Persatuan.

Perhatian Odhy's tampak jelas dengan karakter tokoh yang dibangun melalui sosok Sonik dan Salewan yang berasal dari latar etnis Dayak dan Madura. Meskipun Dayak dan Madura tengah berkonflik waktu itu, Sonik dan Salewan tetap menjalin hubungan baik sebagai sepasang kekasih. Peristiwa tersebut tidak sama-sekali berpengaruh, justru keduanya menyayangkan kejadian tersebut, yang hanya menyisakan kedukaan yang berlarut-larut.

Sebagai sebuah cerita imajinatif tentunya memiliki tujuan utama (maingoal) sebagaimana Odhy's bertujuan mempererat persatuan antaretnis karena dampak berat yang ditanggung pascakonflik di Kalimantan Barat melalui Indahnya Persatuan. Akan tetapi, sosio historis Dayak-Madura masih mengalami gesekan-sosial secara fluktuatif dari tahun ke tahun. Bahkan, pascakonflik 1976 terlihat konflik yang sama masih saja terjadi.

Tentunya, banyak faktor penyebab konflik Dayak-Madura di Kalimantan Barat, hanya saja menurut Arkanudin, lebih disebabkan oleh masalah perbedaan sosial-budaya. Sama halnya, pendapat Koentjaraningrat dan Suparlan bahwa faktor perbedaan budaya yang tercermin dalam perbedaan sistem nilai budaya dan sistem orientasi budaya suatu masyarakat potensial menimbulkan konflik sosial (Arkanudin, 2006: $191 \mathrm{http}: / /$ journal.unisba.ac.id).

Oleh karena itu, mengungkapkan fakta sejarah konflik Dayak-Madura ke dalam sistem imajinasi karya sastra sebagai unit sistem budaya yang kompleks merupakan kontra-budaya atas perbedaan budaya kedua etnis tersebut. Odhy's telah melakukan perlawanan budaya melalui cerpen Indahnya Persatuan dengan mengambil sikap mencari titik-temu perbedaan budaya, baik dalam ranah individu maupun kelompok. Secara individu melalui hubungan Sonik dan Salewan dan 
Tuah Talino

Tahun XIII Volume 13 Nomor 1 Edisi 5 Juli 2019

ISSN 0216-079X

Balai Bahasa Kalimantan Barat

secara kelompok melalui interaksi kelompok dengan latar perbedaan budaya Dayak dan Madura.

Mencari titik-temu dan menghormati budaya yang memang berbeda merupakan langkah yang patut diambil demi meminimalisasi dampak-dampak fakta sejarah konflik antaretnik di Kalimantan Barat. Langkah ini sekaligus memotong peristiwa-peristiwa yang sama di depan demi tetap menghangat dan membaranya api harmonis antaretnis yang pernah dijadikan slogan pemerintahan Kalimantan Barat waktu itu.

\section{SIMPULAN}

Fakta sejarah Indahnya Persatuan adalah peristiwa konflik antaretnik Dayak dan Madura pada 1976 yang bermula dari daerah Sungai Pinyuh Kabupaten Mempawah, dulu Kabupaten Pontianak, dijadikan fakta sejarah di balik karya sastranya. Konflik dipicu oleh pembunuhan orang Dayak oleh orang Madura yang diperingatkan saat merumput (ambil rumput) di pekarangannya.

Fakta sejarah lain di dalam cerpen tersebut adalah koran Akcaya, sebuah koran lokal yang pernah mewarnai jurnalisme Kalimantan Barat sebelum metamorfosis koran Pontianak Post kini. Akcaya disadari oleh Odhy's sebagai media-cetak yang turut berperan mewartakan, baik meletus peristiwa maupun resolusi konflik saat menuju kesepakatan damai antarkedua belah pihak.

Anton Soedjarwo merupakan fakta sejarah yang dihadirkan juga dalam alur penceritaannya dengan perannya mediasi konflik tersebut sehingga bermuara kepada resolusi damai. Perannya diwartakan waktu itu oleh koran Akcaya atas keberhasilannya mendamaikan kedua etnik tersebut. Anton Soedjarwo merupakan perwira kepolisian Indonesia yang pernah menjadi pucuk pimpinan tertinggi di kepolisian Kalimantan Barat yang bernama Kodak pada waktu itu.

\section{DAFTAR PUSTAKA}

Arkanudin. (2006). Menelusuri Akar Konflik Antaretnik di Kalimantan Barat, http://ejournal.unisba.ac.id

Amalia, Dora dkk. (2017). Kamus Besar Bahasa Indonesia Edisi Kelima. Jakarta: Badan Pengembangan dan Pembinaan Bahasa. Kementerian Pendidikan dan Kebudayaan.

Faruk H.T. (2018). Nasionalisme Puitis Sastra, Politik, dan Kajian Budaya. Yogyakarta: Pustaka Pelajar.

Fuad, Khairul dkk. (2008). Ensiklopedi Bahasa Sastra Kalimantan Barat. Pontianak: Balai Bahasa Kalimantan Barat. . (2013). Mukasyafah Cinta Pontianak Dari Menyingkap Sastra Sampai Menyibak Budaya Cuplikan di Borneo Tribune. Pontianak: STAIN Pontianak Press.

Liputan 6. (2001). Dendam Laten di Bumi Borneo. https://www.liputan6.com. Diakses 1 Februari 2019 Pukul 15.00.

Liputan Adil. (1997). "Dari Mana Panas di Kota Sambas". Dalam 2011. Sisi Gelap Kalimantan Barat Perseteruan Etnis Dayak-Madura 1997, Pontianak: Institut Dayakologi dan Institut Arus Informasi. 
Madjid, M. Dien dan Wahyudhi, Johan. (2014). Ilmu Sejarah Sebuah Pengantar. Jakarta: Prenada Media Group.

Mahayana, Maman S. (2005). 9 Jawaban Sastra Indonesia Sebuah Orientasi Kritik. Jakarta: Bening Publishing.

Odhy's. "Indahnya Persatuan" dimuat di Mutiara 30314 September-27 September 1983. Dalam Odhy's. (tanpa tahun). Sunyi Riak Kapuas Kumpulan Cerita Remaja. . (2006). Rahasia Sang Guru Sufi. Yogyakarta: bukulela.

Panitia Penulisan Ensiklopedi Kapolri. (2007). Ensiklopedi Kapolri Refleksi Pers 1945 - 2006 Ensiklopedi Kapolri Jendral Polisi Anton Soedjarwo. Panitia Penulisan Ensiklopedi Kapolri: Bandung.

Ratna, Nyoman Kutha. (2013). Paradigma Sosiologi Sastra. Yogyakarta: Pustaka Pelajar.

Santoso, Puji dan Djamaris. (2014). Kritik Sastra Terapan. Yogyakarta: Elmatera Semi, Atar. (2013). Kritik Sastra. Bandung: CV Angkasa.

Tanasaldy, Taufiq, (2012). Regime Change and Ethnic Politics in Indonesia. Leiden: KITLV Press.

Pontianak Post, "Merawat Kenangan 46 Tahun Pontianak Post". Sabtu 2 Februari 2019: hlm 1. 